\title{
Commentary: Mitral valve repair: Voodoo, art, and science
}

\author{
Marc Gillinov, MD, Daniel J. P. Burns, MD, MPhil, \\ and Per Wierup, MD, PhD
}

More than half a century after Carpentier established a set of principles for repairing degenerative mitral valves, new and experienced surgeons alike continue to strive to unlock the mysteries that will enable them to repair these valves. Why does this discussion continue? Surgeons quickly master coronary artery bypass grafting and aortic valve replacement. Mitral valve repair is different. Most surgeons do not have a large volume of patients with degenerative mitral valve disease, and this limits their ability to become facile with repair techniques. ${ }^{1}$ In addition, almost every valve presents nuanced challenges. There is really no "simple P2 prolapse." Patients with P2 prolapse may also have excess leaflet height, restriction of P1, annular calcification, a bulging septum, and a variety of other findings that require attention to secure a good repair. Finally, the dialogue concerning mitral valve repair can be confusing. Surgeons constantly debate the merits of resection versus artificial chordae, complete versus partial rings, the Alfieri stitch versus traditional techniques, and even repair versus replacement in selected patients. Given all of these considerations, one might conclude that mitral valve repair requires a combination of art, experience, and a little bit of voodoo. $^{2}$ To this discussion, McCarthy and colleagues ${ }^{3}$ bring math and science.

Using only 2 measurements-the anterior leaflet height and the C-Sept distance-McCarthy and colleagues ${ }^{3}$

From the Department of Thoracic and Cardiovascular Surgery, Cleveland Clinic, Cleveland, Ohio.

Disclosures: Dr Gillinov serves as a consultant to Edwards Lifesciences, Medtronic, CryoLife, Abbott, AtriCure, Johnson and Johnson, and ClearFlow. Dr Burns serves as a consultant to Medtronic. Dr Wierup serves as a consultant to Edwards Lifesciences, Medtronic, and CryoLife.

The Journal policy requires editors and reviewers to disclose conflicts of interest and to decline handling or reviewing manuscripts for which they may have a conflict of interest. The editors and reviewers of this article have no conflicts of interest.

Received for publication Oct 11, 2020; revisions received Oct 11, 2020; accepted for publication Oct 14, 2020; available ahead of print Oct 17, 2020

Address for reprints: Marc Gillinov, MD, Department of Thoracic and Cardiovascular Surgery, Cleveland Clinic, Desk J4-1, 9500 Euclid Ave, Cleveland, OH 44195 (E-mail: gillinom@ccf.org).

J Thorac Cardiovasc Surg 2022;164:878-9

0022-5223/\$36.00

Copyright (c) 2020 by The American Association for Thoracic Surgery

https://doi.org/10.1016/j.jtcvs.2020.10.043

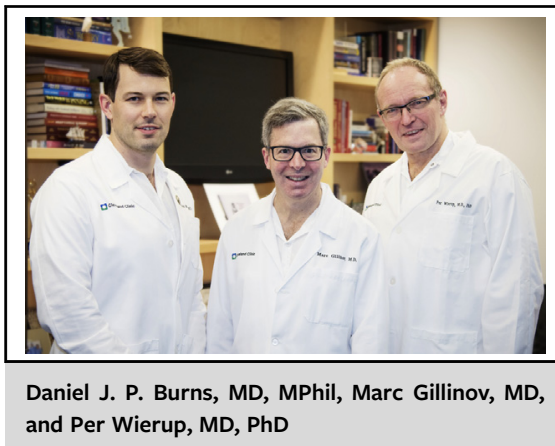

CENTRAL MESSAGE

Mitral valve repair requires both a plan and mastery of surgical techniques to execute the plan. Measurement of anterior leaflet height informs one approach to creating a plan for repair.

provide a simple formula designed to create a competent valve with a coaptation length of 5 to $10 \mathrm{~mm}$ while avoiding systolic anterior motion. In general, this is achieved by adjusting the height of the posterior leaflet and choosing a ring of appropriate size, both maneuvers based on the anterior leaflet height. The annuloplasty size can be modulated according to the perceived risk of systolic anterior motion or the presence of an unusually short posterior leaflet. This adjustment in annuloplasty size highlights the necessity for judgment (what some would call "art") in execution of the repair.

With 2 measurements and straightforward math, McCarthy and colleagues ${ }^{3}$ achieve outstanding early and late results. Surgeons seeking to develop their mitral repair practice should read this article carefully and both understand the authors' approach and note that many patients required more than posterior leaflet resection and annuloplasty. Clefts and indentations were closed routinely, edge-to-edge repairs were used, and anterior leaflet prolapse was generally treated by chordal transfer when the prolapse was not at a commissure. The suite of repair techniques used resulted in successful outcomes; however, surgeons should also recognize that excellent repairs can also be achieved with flexible bands and creation of artificial 
chordae. The point is that the surgeon can begin with this formula, but must develop an appreciation for the nuances of valve repair and expertise with a variety of repair techniques to achieve good results. The surgeon must bring both a plan and the skill to execute it. McCarthy and colleagues ${ }^{3}$ provide a plan.

\section{References}

1. Bolling SF. Can we predict mitral valve repair rates by individual surgeons' mitral volume? Tex Heart Inst J. 2011;38:703-4.

2. Bothe W, Miller DC, Doenst T. Sizing for mitral annuloplasty: where does science stop and voodoo begin? Ann Thorac Surg. 2013;95:1475-83.

3. McCarthy PM, Herborn J, Kruse J, Liu M, Andrei A-C, Thomas JD. A multiparameter algorithm to guide repair of degenerative mitral regurgitation. J Thorac Cardiovasc Surg. 2022;164:867-76.e5.
See Article page 867 .

\section{Commentary: Repair of degenerative mitral regurgitation: Science, art, or both?}

\author{
Manuel J. Antunes, MD, PhD, DSc
}

Degenerative mitral valve regurgitation (MR) is the most common infirmity affecting the left atrioventricular valve and mitral valve repair (MVRep) is now the indicated method of treatment (class I) with widely reported excellent and durable results. The principles and techniques of MVRep are fairly well standardized, albeit with some controversy still surrounding the choice of preserve versus resect leaflet tissue, the use of artificial chordae, and type of ring/band for the annuloplasty. The aim is a perfectly competent valve with no residual prolapse ensured by adequate coaptation of the leaflet's free edge. Experienced surgeons should be able to repair the vast majority of these valves, irrespective of the extension of the disease, and capable of anticipating a good result before closing the left atrium supported by intraoperative transesophageal echocardiography before termination of cardiopulmonary bypass. ${ }^{1}$

McCarthy and colleagues ${ }^{2}$ propose a measured algorithm that should increase the precision and reproducibility of

\footnotetext{
From the Faculty of Medicine, Clinic of Cardiothoracic Surgery, University of Coimbra, Coimbra, Portugal.

Disclosures: The author reported no conflicts of interest.

The Journal policy requires editors and reviewers to disclose conflicts of interest and to decline handling or reviewing manuscripts for which they may have a conflict of interest. The editors and reviewers of this article have no conflicts of interest.

Received for publication Oct 2, 2020; revisions received Oct 2, 2020; accepted for publication Oct 5, 2020; available ahead of print Oct 10, 2020.

Address for reprints: Manuel J. Antunes, MD, PhD, DSc, Faculty of Medicine, University of Coimbra, 3000-548 Coimbra, Portugal (E-mail: mjantunes48@sapo.pt). J Thorac Cardiovasc Surg 2022;164:879-80 $0022-5223 / \$ 36.00$

Copyright (c) 2020 by The American Association for Thoracic Surgery https://doi.org/10.1016/j.jtcvs.2020.10.012
}

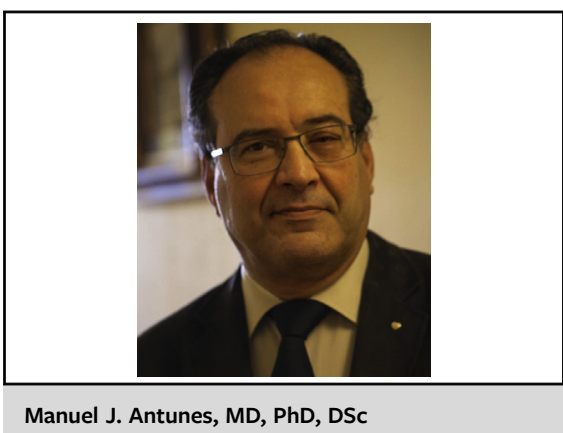

CENTRAL MESSAGE

There is a tremendous amount of science, precision, and calculated decision making within the practice of surgery. But something just seems to make outcomes better for some than for others-art!

repair in degenerative MR. To this aim, they made direct and echocardiographic measurements of the leaflet size and coaptation, and anteroposterior ring dimension in 1051 patients operated on by the senior surgeon (Dr McCarthy, referred to from here on as "the surgeon") during a 13-year period, of whom $1026(97.6 \%)$ had their valve repaired. Ten-year freedom from mitral reoperation was $99.7 \%$ and only $1.4 \%$ of patients had significant recurrent MR $(\geq 3+)$. The authors concluded that "a simple, reproducible, measured algorithm for MVRep provides excellent early and late results and is a useful adjunct to established surgical techniques."

To me, the obvious conclusion is that the surgeon achieved excellent results before he developed and started using the algorithm and there is no evidence that its use will have a notable influence in the practice of any other surgeon. The authors tell us that residents and visitors have 